\title{
“IT'S LOBBYING, STUPID!”: COMO GRUPOS DE INTERESSE ESTRANGEIROS AFETAM AS NEGOCIAÇÕES COMERCIAIS BRASILEIRAS
}

\section{"It's lobbying, stupid!": How foreign interest groups impair" Brazilian trade negotiations}

\author{
Pedro Henrique de Souza Netto ${ }^{1}$
}

Em 1992, o então presidente norte-americano George Bush esperava vencer as eleições com facilidade. Em seu governo, os Estados Unidos consolidavam seu papel de maior potência mundial e, internacionalmente, haviam vencido a Guerra do Golfo. Contudo, a equipe de propaganda de seu oponente, Bill Clinton, apostou que os triunfos internacionais do Estado americano seriam um assunto menor naquela eleição, consolidando seu pensamento na frase "É a economia, estúpido! ”. De forma similar, as atuais dificuldades de negociação comercial do Brasil para produtos agropecuários são causadas menos por governos estrangeiros, e mais pelos interesses econômicos de grupos de pressão daqueles países.

Nos últimos anos, o Brasil modificou sua política comercial e passou a dar maior importância a novos acordos comerciais. Ainda sob a presidência de Dilma Rousseff, o Plano Nacional de Exportações (MDIC, 2015) se propunha, entre outros aspectos, a ampliar as negociações comerciais do país. No governo Michel Temer, o Ministro José Serra (2016), por sua vez, declarou em seu discurso de posse que daria início a um "acelerado processo de negociações”. No discurso oficial brasileiro, a busca por acordos é prioridade da política comercial há pelo menos três anos.

De fato, o país buscou avançar sua agenda de acordos comerciais no período. Desde 2015, o Brasil trocou ofertas de redução tarifária com a União Europeia, negociou a ampliação de seu acordo com o México e, em janeiro de 2017, lançou as negociações entre Mercosul e a Associação Europeia de Livre Comércio (EFTA). Simultaneamente, foram discutidos acordos de escopo limitado, como a ampliação do Acordo de Comércio Preferencial com a Índia e os Acordos de Cooperação e Facilitação de Investimentos (ACFIs). Ainda houve consultas públicas sobre negociações comerciais com Coréia do Sul, Japão, Tunísia e Líbano.

\footnotetext{
${ }^{1}$ Pedro Netto é mestrando em Relações Internacionais na Universidade de Brasília e assessor de Negociações Internacionais e Inteligência Comercial na Confederação da Agricultura e Pecuária do Brasil (CNA). As opiniões aqui expressas são de responsabilidade do autor e não refletem necessariamente a posição da Confederação da Agricultura e Pecuária do Brasil (CNA). Email: pedro.hsnetto@gmail.com
} 
Atualmente, o Brasil negocia ou tem interesse em negociar acordos com países que respondem por cerca de 36\% do PIB global (BANCO MUNDIAL, 2017).

Apesar dessas ações, o setor agropecuário brasileiro tem encontrado sérias dificuldades nas negociações do país. Segundo Décio Coutinho, Consultor de Produção Animal da Confederação da Agricultura e Pecuária do Brasil (CNA), a União Europeia “desrespeitou os países do bloco sul-americano [Mercosul]" (MICHALOPOULOS, 2016) ao apresentar uma oferta de redução tarifária que não amplia o acesso aos mercados europeus de carne bovina e etanol. Em um artigo intitulado "É preciso exportar mais", o presidente da CNA, João Martins da Silva Júnior (2016), apontou que "ao retomar as conversas com o México em meados do ano passado, o espaço destinado à agropecuária continua diminuto diante da potencialidade do setor". Esses fatos demonstram que, apesar de o Brasil avançar em negociações internacionais, a agropecuária brasileira segue com dificuldades para avançar rumo a novos mercados.

Quais seriam as razões para essa situação? Academicamente, é possível adaptar as teorias sobre mudanças institucionais e reformas econômicas para analisar as negociações comerciais do Brasil.

Segundo Pedersen (2000), há três possíveis causadores para mudanças em políticas econômicas: o Estado, influências internacionais e a sociedade. O Estado poderia ampliar ou não a abertura comercial de um país em razão de mudanças em sua estrutura burocrática e na ideologia do governo, entre outros. Já as influências internacionais poderiam ocorrer por meio de pressão de outros governos ou organizações internacionais. Finalmente, a sociedade influenciaria a política comercial de um país principalmente por meio da pressão de grupos que representam os interesses de partes daquela sociedade, como seus setores empresariais. Haveria, portanto, três possíveis causas para as dificuldades da agropecuária brasileira em negociações internacionais: o país com o qual o Brasil negocia não teria interesse em um acordo; ele teria interesse, mas fatores internacionais o pressionam e, assim, impedem que apresente ofertas interessantes para a agropecuária brasileira; ou grupos de interesse dificultam esse resultado.

A primeira possível explicação, de que os Estados negociadores são contrários a uma negociação ampla, é improvável. Ao lançar negociações que envolvem o Brasil, os políticos e as burocracias europeia e mexicana evidentemente reconheciam a necessidade de um acordo que levasse em conta o principal setor exportador daquele país. Desde então, a liderança da Comissão Europeia e do México se mantém sob os mesmos partidos políticos (a ALDE segue na Comissão Europeia de Comércio e o PRI segue na Secretaria de Economia mexicana), dificultando argumentos ligados à ideologia do governo. Do mesmo modo, entre o lançamento das negociações e a atualidade, não houve mudanças significativas na estrutura burocrática e institucional dos dois países. Recentemente, a Comissária Europeia de Comércio, Cecilia Malmström (2017), reafirmou que acredita que "se trabalharmos juntos podemos chegar a um bom acordo equilibrado em que todos somos ganhadores”. É possível argumentar que poderia existir uma mentalidade histórica de proteção ao pequeno agricultor entre as duas burocracias governamentais, mas é improvável que essa mentalidade, isoladamente, seja suficiente para impedir avanços nas negociações comerciais. Dessa forma, o Estado mexicano e a Comissão Europeia, e suas burocracias, parecem ter responsabilidade limitada pelos restritos resultados das negociações agropecuárias e agroindustriais brasileiras. 
No tocante a influências internacionais, a pouca ação de organizações como FMI, Banco Mundial e OMC tem sido contrabalanceada por eventos nacionais. A vitória do Brexit, no Reino Unido, as eleições de Donald Trump, nos Estados Unidos, e da França e Alemanha, na Europa, além dos embargos russos a alimentos europeus, apontam para um crescimento do nacionalismo que tende a afetar acordos comerciais.

Até o momento, contudo, esses eventos tiveram impacto limitado nas negociações brasileiras. A União Europeia, seriamente impactada pelo Brexit e enfrentando processos eleitorais em países como França e Alemanha, apresentou ao Mercosul suas listas de redução tarifária que excluíam etanol, açúcar e carne bovina um mês e meio antes do referendo no Reino Unido (DANTAS, 2017). Os embargos da Rússia, por sua vez, podem ter levado a um excesso de oferta de carne suína e de frutas no mercado europeu, mas há indicação de que essas mercadorias tenham, em grande parte, sido escoadas para terceiros mercados (CNA, 2016a). Na América, a eleição de Donald Trump e a renegociação do NAFTA podem até mesmo ter ampliado o interesse mexicano ${ }^{2}$ na discussão sobre a ampliação do ACE-53 com o Brasil - a qual não tem, todavia, prazo para terminar (MÉXICO, 2017). No decorrer de 2017, é possível que as incertezas do Brexit, os ciclos eleitorais europeus e as incertezas na América do Norte tenham afetado a velocidade das negociações com União Europeia e México. De todo modo, não seria plausível relacionar o Brexit e a eleição de Donald Trump às dificuldades de negociação da agropecuária brasileira ocorridas nos últimos dois anos, e os embargos russos dificilmente afetaram as ofertas europeias de mercadorias como carne bovina e etanol.

Finalmente, é necessário analisar a atuação de grupos de interesse nesses países. No México, o presidente do Conselho Nacional Agropecuário, Benjamín Grayeb (2016, tradução nossa) afirmou em entrevista que o setor agropecuário de seu país não teria vantagens com um acordo com o Brasil, e mencionou que "não, nós como setor não queremos a abertura". Segundo a imprensa especializada mexicana, o grupo utilizou questões sanitárias e fitossanitárias para solicitar, junto à Secretaria de Economia do México, a exclusão completa de mercadorias agropecuárias das negociações em curso (PEREA, 2016). Já na União Europeia, a maior organização representativa dos produtores, a Copa-Cogeca, é uma antiga opositora de um acordo comercial agropecuário com o Mercosul. O grupo afirma que a redução da proteção europeia para setores como carne bovina seria extremamente nociva, principalmente em razão da sanidade animal, rastreabilidade e sustentabilidade da pecuária brasileira (LIVINGSTONE, 2016; ROUSSEAU, 2016). Além dessas organizações de amplo escopo, associações setoriais ou nacionais como a Confederação de Suinocultores do México e a Associação de Fazendeiros da Irlanda também atuam contra acordos que abarquem mercadorias agropecuárias por meio de reuniões com o governo, cartas a tomadores de decisão e declarações públicas (MALMSTRÖM, 2016; PEREA, 2016; ROUSSEAU, 2016). Os grupos de interesse mexicanos e europeus têm, portanto, atuado sistematicamente contra acordos comerciais que ampliem o acesso do setor agropecuário brasileiro a seus mercados.

É possível dizer que os lobbies agrícolas mexicano e europeu são os principais responsáveis pela dificuldade nas negociações comerciais agropecuárias entre o Brasil e seus parceiros. Uma eventual tendência das burocracias estatais europeia e mexicana a proteger seus setores rurais dificilmente resistiria

\footnotetext{
${ }^{2}$ Na nota de imprensa disponibilizada após a Rodada de Negociações em Brasília (junho de 2017), o governo do México (2017) apontou que "La negociación entre México y Brasil forma parte de la agenda de diversificación comercial que impulsa el Gobierno de la República".
} 
a pressões políticas para a elaboração de um acordo, e os grandes fenômenos internacionais dos últimos anos (sanções russas, Brexit e eleição de Donald Trump) ainda são demasiado recentes, ou têm impacto limitado a poucos setores. Grupos de interesse do México e da União Europeia, por outro lado, têm levado sua oposição a esses acordos à mídia e a instituições governamentais, pressionando negociadores a apresentar ofertas mais conservadoras para Brasil e Mercosul. Se quiser acordos comerciais que ampliem o acesso de sua agropecuária aos mercados mexicano e europeu, o Brasil precisa lidar com os grupos de interesse desses países.

Não é, contudo, apenas no México e Europa que grupos de interesse atuam para ampliar a proteção aos setores agropecuários. O Brasil está em estágios iniciais ou prévios a negociações com Japão, Coreia do Sul, EFTA, Índia, Tunísia e Líbano. No Japão, a União Central de Cooperativas Agrícolas (JA-Zenchu) foi fortemente contrária à discussão da TPP e, apesar da grande liberalização envolvida naquele acordo, o Japão foi um dos poucos países que mantiveram cotas tarifárias para produtos como lácteos, feijões, trigo, cevada, milho, arroz e derivados (CNA, 2016b; MACLACHLAN; SHIMIZU, 2014). Em 2015, a Federação Avançada dos Fazendeiros Coreanos (KAFF) e a Liga Camponesa Coreana (KPL) protestaram, inclusive por meios violentos, contra a abertura comercial para arroz num possível acordo com a China (NAWAKURA, 2016). Na EFTA, a Uniterre suíça organizou manifestações contra a abolição do sistema de cotas de leite e a Associação Agrária Norueguesa (Norges Bondelag) anunciou, ainda em 2016, que era contrária a concessões ao Mercosul nos setores de carnes, cereais, frutas e hortaliças (BARTNES; SKORGE, 2016; FOULKES, 2009). Nos países e blocos desenvolvidos com os quais o Brasil deve ampliar suas negociações no futuro próximo, o lobby agropecuário tem histórico de atuar contra a liberalização comercial de produtos agropecuários.

Apesar de algumas diferenças, países emergentes seguem dinâmica semelhante. A Índia, única dessas regiões com quem o Brasil negocia no momento, não possui um grupo de pressão agropecuário de amplo escopo no nível nacional. Essa realidade não significa, contudo, que o lobby não exista: a Associação Indiana dos Moinhos de Açúcar (ISMA), por exemplo, é reconhecida por buscar a ampliação de tarifas para açúcar e etanol em anos de baixa safra (BHOSALE, 2017; DE, 2017). O Líbano tem uma situação similar à indiana, onde associações setoriais como o Sindicato de Indústrias Alimentícias Libanesas organizam lobby de forma não-sistemática e via conexões pessoais (MUIT et al., 2015). Apesar de a agropecuária tunisiana ser mais complementar à brasileira, o lobby agropecuário local também tende a dificultar uma futura negociação - a União Tunisiana da Agricultura e da Pesca (UTAP) já se mobilizou contra importações de cordeiros, tomates e pimentas e tem se preocupado com a produção local de laranjas (HIJBA, 2017; La Tunisie, 2017; Tunisie..., 2013). Apesar de geralmente contarem com grupos de interesse menos organizados, os países em desenvolvimento também possuem algum nível de lobby agropecuário que tende a dificultar as negociações de produtos agropecuários brasileiros.

Considerando a importância que a retórica governamental brasileira dá às exportações do setor (RITTNER, 2017), e o evidente interesse da agropecuária nacional em ampliar suas vendas externas, são necessárias ações estatais e privadas para lidar com o lobby estrangeiro. Por parte do governo, é importante que os negociadores deixem clara, a suas contrapartes internacionais, a importância da agropecuária para a 
assinatura de acordos comerciais com o Brasil. O setor privado nacional, por sua vez, deve responder às ações dos grupos de interesse estrangeiros, contra argumentando suas declarações com informações precisas. A boa recepção, pela imprensa internacional, da resposta da CNA brasileira a declarações da CopaCogeca (GREEN, 2016; LIVINGSTONE, 2016) demonstra que esse tipo de ação movimenta o debate no exterior, fortalecendo a posição negociadora do Brasil. O sucesso do setor agropecuário nacional nas negociações do país depende tanto de ações governamentais quanto de iniciativas do setor privado nacional, por meio de ações inteligentes que contrabalanceiem o lobby estrangeiro. It’s lobbying, stupid!

\section{REFERÊNCIAS}

BANCO MUNDIAL. World Bank Data: Free and open access to global development data. 2017. Base de dados. Disponível em: <http://data.worldbank.org/>. Acesso em: 17 jan. 2017.

BARTNES, Lars P.; SKORGE, Per. Norge må ikke gi innrømmelser til Mercosur på landbruksområdet. Oslo: Norges $\quad$ Bondelag, $2016 . \quad$ Disponível em: <https://www.bondelaget.no/getfile.php/13738515/Dokumenter/Innledende\%samtaler\%med\%Merc osur.pdf >. Acesso em: 25 jul. 2017.

BHOSALE, Jayashree. Sugar lobby seeks stabilisation fund. The Economic Times. Mumbai: Bennett, Coleman \& Co. Ltd., 25 jul. 2017. Disponível em: $<$ http://economictimes.indiatimes.com/markets/commodities/news/sugar-lobby-seeksstabilisation-fund/articleshow/59380231.cms>. Acesso em: 25 jul. 2017.

CNA - CONFEDERAÇÃO DA AGRICULTURA E PECUÁRIA DO BRASIL. Impactos da parceria Transpacífico na agropecuária brasileira. Brasília: CNA, 2016 (b). Disponível em: $<$ http://www.cnabrasil.org.br/noticias/cna-publica-estudo-sobre-o-impacto-da-tpp-paraagropecuaria-brasileira>. Acesso em: 24 jul. 2017.

CNA - CONFEDERAÇÃO DA AGRICULTURA E PECUÁRIA DO BRASIL. Os embargos russos e a agropecuária brasileira. Boletim do Agronegócio Internacional. Brasília, p. 1-2. nov. 2016 (a).

DANTAS, Fernando. "Agora vai? Embaixador Carlos Márcio Cozendey vê chances de conclusão do acordo entre União Europeia e Mercosul, como reação a Trump.”. O Estado de São Paulo. São Paulo, 08 mar. 2017. Disponível em: <http://economia.estadao.com.br/blogs/fernando-dantas/agora-vai/>. Acesso em: 24 jul.2017.

DE, Arindam. Low inflation not at the cost of farmers. India Today. Nova Delhi: Living Media, 15 jul. 2017. Disponível em: <http://indiatoday.intoday.in/story/low-inflation-farmers-modi-cpiwpi/1/1003091.html>. Acesso em: 25 jul. 2017.

FOULKES, Imogen. Swiss dairy farmers face uncertain future. Deutsche Welle. Bonn, 06 out. 2009. Disponível em: <http://www.dw.com/en/swiss-dairy-farmers-face-uncertain-future/a-4758246>. Acesso em: 25 jul. 2017.

GRAYEB, Benjamín. “'Brasil no es confiable’: CNA”. 24 fev. 2016. El Economista. Entrevista concedida a MORALES, Roberto. Disponível em: <http://eleconomista.com.mx/industrias/2016/02/24/brasil-noconfiable-cna>. Acesso em: 17 jan. 2017.

GREEN, Max. Brazil farm lobby slams ‘defamatory’ EU campaigns on beef. Agra Europe. Londres, 19 dez. 2016. Disponível em: <https://www.agra-net.com/agra/agra-europe/meat-livestock/beef/brazilfarm-lobby-slams-defamatory-eu-campaigns-on-beef-536431.htm>. Acesso em: 17 jan. 2017. 
HIJBA, Amal. Tunisie-Marchandises turques: Les commerçants en profitent, l'industrie et l'agriculture en pâtissent. Huff Post Tunisie. S.l.: s.n., 02 jul. 2017. Disponível em: <http://www.huffpostmaghreb.com/2017/07/02/tunisie-marchandises-turq_n_17367798.html>. Acesso em: 25 jul. 2017.

LA TUNISIE CROULE SOUS LES ORANGES. Le Figaro Économie. S.l.: Le Figaro, 09 jan. 2017. Disponível em: $\quad<$ http://www.lefigaro.fr/conjoncture/2017/01/09/20002-20170109ARTFIG00171-la-tunisiecroule-sous-les-oranges.php >. Acesso em: 25 jul. 2017.

LIVINGSTONE, Emmet. Speaking of Mercosur... Politico Pro. Bruxelas, p. 00-00. 19 dez. 2016.

MACLACHLAN, Patricia; SHIMIZU, Kay. Showdown: The Trans-Pacific Partnership vs. Japan's Farm Lobby. The National Interest. S.1.: Center for the National Interest, 02 out. 2014. Disponível em: $<$ http://nationalinterest.org/blog/the-buzz/showdown-the-trans-pacific-partnership-vs-japansfarm-lobby-11394>. Acesso em: 24 jul. 2017.

MALMSTRÖM, Cecilia. Los benefícios de la liberalización del comercio com el Mercosur. Madri: Comissão Europeia, 03 jul. 2017. Disponível em: <http://trade.ec.europa.eu/doclib/docs/2017/july/tradoc_155687.pdf>. Acesso em: 23 jul. 2017.

MDIC - MINISTÉRIO DA INDÚSTRIA, COMÉRCIO EXTERIOR E SERVIÇOS. Ampliação do ACP Mercosul Índia. Brasília, 2017. Disponível em: <http://www.mdic.gov.br/comercio-exterior/negociacoesinternacionais/9-assuntos/categ-comercio-exterior/1567-ampliacao-do-acp-mercosul-india>. Acesso: 17 jan. 2017

MDIC - MINISTÉRIO DA INDÚSTRIA, COMÉRCIO EXTERIOR E SERVIÇOS. Plano Nacional de Exportações 2015-2018. Brasília, 24 jun. 2015. Disponível em: <http://www.desenvolvimento.gov.br/arquivos/dwnl 1435244583.pdf >. Acesso: 08 fev. 2016

MÉXICO. SECRETARÍA DE ECONOMIA. . México y Brasil concluyen la Sexta Ronda de Negociación del ACE53. S.l: S.n., 2017. 1 p. Disponível em: <https://www.gob.mx/se/prensa/mexico-y-brasilconcluyen-la-sexta-ronda-de-negociacion-del-ace-53>. Acesso em: 23 jul. 2017.

MICHALOPOULOS, Sarantis. EU's decision on beef and ethanol 'disrespected' Mercosur countries. Euractiv: EU news and policy debates across languages. S.l., p. 00-00. 24 maio 2016. Disponível em: <http://www.euractiv.com/section/agriculture-food/news/eus-decision-on-beef-and-ethanoldisrespected-mercosur-countries/>. Acesso em: 17 jan. 2017.

MUIR, Douglas et al. Increasing Enterprise Growth and Jobs in Lebanon: Options to increase SME growth and jobs. S.l: USAID, 2015. 117 p. Produzido para a Agência dos Estados Unidos para o Desenvolvimento Internacional (USAID). Disponível $<$ http://pdf.usaid.gov/pdf_docs/PA00KQ86.pdf>. Acesso em: 26 jul. 2017.

NAWAKURA, Akio. The Impact of Farmers' Resistance on Trade Liberalization: A Comparative Study on Political Process around FTAs in Korea and Japan. In: The Asian Conference on Politics, Economics \& Law, 2016, Kobe. Official Conference Proceedings. Kobe: The International Academic Forum, 2016.

PEDERSEN, Jorgen D. Explaining Economic Liberalization in India: State and Society Perspectives. World Development, S.1., v. 28, n. 2, p.265-282, 2000.

PEREA, Ernesto. Pide el CNA a SE excluir al sector agropecuario mexicano del acuerdo con Brasil. Imagen Agropecuaria. S.l., 31 jul. 2016. Disponível em: $\lfloor$ http://imagenagropecuaria.com/2016/pide-cnaexcluir-al-sector-agropecuario-mexicano-en-acuerdo-brasil/>. Acesso em: 17 jan. 2016.

RITTNER, Daniel. Em Davos, país quer mudar 'imagem distorcida' do agronegócio. Valor Econômico. Davos, 16 jan. 2017. Disponível em: <http://www.valor.com.br/brasil/4836884/emdavos-pais-quer-mudar-imagem-distorcida-do-agronegocio>. Acesso em: 17 jan. 2017. 
ROUSSEAU, Oscar. Copa-Cogeca slams 'unacceptable' EU-Mercosur deal. Global Meat News. S.l., 12 abr. 2016. Disponível em: <http://www.globalmeatnews.com/Industry-Markets/Copa-Cogeca-slamsunacceptable-EU-Mercosur-deal>. Acesso em: 17 jan. 2017.

SERRA, José. Discurso do ministro José Serra por ocasião da cerimônia de transmissão do cargo de ministro das Relações Exteriores. 2016. Disponível em: <http://www.itamaraty.gov.br/ptBR/discursos-artigos-e-entrevistas/ministro-das-relacoes-exteriores-discursos/14038-discurso-doministro-jose-serra-por-ocasiao-da-cerimonia-de-transmissao-do-cargo-de-ministro-de-estadodas-relacoes-exteriores-brasilia-18-de-maio-de-2016>. Acesso em: 17 jan. 2017.

SILVA JÚNIOR, João Martins da. É preciso negociar mais. Comex do Brasil. Brasília, p. 0-0. 26 abr. 2016. Disponível em: <https://www.comexdobrasil.com/e-preciso-negociar-mais/>. Acesso em: 17 jan. 2017.

TUNISIE: Polémique autor d'une nouvelle importation massive de moutons pour l'Aïd. Huff Post Tunisie. S.l.: Huff Post Maghreb, 12 set. 2013. Disponível em: <http://www.huffpostmaghreb.com/2013/09/12/polemique-importation-moutonsaid_n_3913440.html>. Acesso em: 25 jul. 2017. 


\section{RESUMO}

Nos últimos anos, o Brasil modificou sua política comercial e passou a buscar novos acordos comerciais. Apesar disso, há sérias dificuldades nas negociações de produtos agropecuários. Grupos de interesse estrangeiros têm papel relevante nesses empecilhos, e devem ser lembrados nas ações dos setores público e privado brasileiro.

Palavras-chave: Grupos de Interesse; Negociações Comerciais; Agropecuária;

\section{ABSTRACT}

Over the last years, Brazil has aimed its trade policy at new trade agreements. Nevertheless, the country's trade negotiations face serious difficulties in what regards agricultural goods. The foreign lobby has a relevant role in such deadlocks, and Brazilian public and private sectors' actions should bear it in mind.

Key-words: Interest groups; Trade negotiations; Agribusiness. 